\section{Long term outcome of acquired food allergy in pediatric liver recipients: a single center experience}

\author{
Antigoni Mavroudi, 1 loannis Xinias, 1 \\ Aristidis Deligiannidis, 2 \\ Efthimia Parapanissiou, 2 George Imvrios 3 \\ 1Third Pediatric Department, \\ 2Immunology Department, Regional \\ Tissue Typing Lab, 3Organ \\ Transplantation Unit, Hippokratio \\ Hospital, Aristotle University \\ of Thessaloniki, Greece
}

\section{Abstract}

Food induced sensitization has been reported in pediatric liver recipients. However long term follow up has not been established so far.

We report here our experience regarding 3 pediatric patients who developed acquired food allergy after liver transplantation. The first patient suffered from persistent diarrhea and eczema. The second one presented with abdominal pain with no signs of rejection, abdominal discomfort, vomiting when ingesting milk proteins and responded well to the elimination diet. The third patient presented with facial angioedema and hoarseness of voice. She had multiple food allergies and reacted to milk, egg and sesame. All the patients had elevated total Immunoglobulin $\mathrm{E}$ $(I g E)$ and elevated specific $I g E$ antibodies to the implicated food allergens. The first patient presented clinical manifestations of allergy when she was 19 months old. The second patient became allergic at the age of 16 and the third patient at the age of 3 . The symptoms of food allergy persisted for 8 years in the first case and for 2 years in the other two cases. Low levels of specific $\operatorname{Ig} E$ antibodies to the implicated food allergens and an enhanced Thelper 1 cell immune response toward interferon-gamma production were markers of tolerance acquisition. The long term prognosis in our cases was excellent. Food allergy resolved in all the patients. The long term prognosis of acquired food allergy after liver transplantation is currently obscure. More studies would be needed including greater number of patients to determine whether acquired food allergy is transient in pediatric liver recipients.

\section{Introduction}

Food induced sensitization to various food allergens has been reported in pediatric liver recipients after orthotopic liver transplantation. The increased prevalence of food allergy was noted in tacrolimus-immunosuppressed pediatric liver recipients ranging from $10 \%$ to 17\%.1 Post-Transplant Food Allergy (PTFA) although ascribed to tacrolimus treatment by various authors tacrolimus treatment alone cannot account for the development of food allergy after liver transplantation. In adults the only cases of post-transplant sensitization to food allergens have occurred via passive transfer from food allergic donor. ${ }^{2}$

The phenomenon is consistent with previous findings of allergy transfer via bone marrow transplantation and the finding that donor derived stem cells present in a liver graft can sustain long-term hematopoiesis in a recipient. ${ }^{3,4}$ However, the development of a new food allergy after liver transplantation has been reported in children receiving liver grafts from donors with no known food allergy. ${ }^{2}$

We present three out of twenty pediatric liver recipients followed in our center who developed food allergy after receiving liver transplants from donors with no documented history of food allergy. Possible mechanisms underlying the development of food allergy after transplantation are discussed. Long term follow up in all three cases has provided evidence on the prognosis of PTFA.

\section{Case \#1}

The case involves a 10-year-old girl who underwent orthotopic liver transplantation (OLT) for extrahepatic biliary atresia at 7 months of age. The child has a positive family history of atopy as her mother has asthma. The transplant was from a deceased donor with no history of atopy. Her post operative growth improved satisfactorily. The child's weight ascended from the $9^{\text {th }}$ percentile before operation to the $25^{\text {th }}$ percentile, while her height remained on the $25^{\text {th }}$ percentile. Methylprednisolone, azathioprine and tacrolimus immunosuppression were initially used. Tacrolimus therapy was continued at a dose of 0.5 $3 \mathrm{mg} / \mathrm{Kg} /$ day achieving a serum level of $2-10$ $\mathrm{ng} / \mathrm{mL}$.

Prior to transplantation the child followed an unrestricted diet with no history of adverse food reaction. Twelve months after OLT, she presented mucoid bloody stools. Her laboratory investigation revealed leukocyte count of $9.3 \times 103 / \mathrm{mm}^{3}$, with $41 \%$ neutrophils, $42 \%$ lymphocytes, $7.5 \%$ monocytes and $5 \%$ eosinophils (normal $<6 \%$ ). The ESR was $5 \mathrm{~mm} / \mathrm{h}$. The total IgE was $29 \mathrm{UL} / \mathrm{mL}$ (normal range:0-50). Her platelet count was normal. The liver enzymes were not elevated and the prothrombin time (PT) and the Activated Partial Thromboplastin Time (PTT) were not prolonged. The liver biop-
Correspondence: Antigoni Mavroudi, Third Pediatric Department, Hippokratio Hospital, Aristotle University of Thessaloniki, 66 Spirou Loui St., 54352 Pilea - Konstantinopolitika,

Thessaloniki, Greece.

Tel. +30.2310 .909632 - Fax: +30.2310 .992981 .

E-mail: antigonemavrudi@gmail.com

Key words: liver transplantation, acquired food allergy, children, long term follow up.

Received for publication: 28 November 2011.

Revision received: 2 January 2012.

Accepted for publication: 2 January 2012.

This work is licensed under a Creative Commons Attribution NonCommercial 3.0 License (CC BYNC 3.0).

(C) Copyright A. Mavroudi et al., 2012

Licensee PAGEPress, Italy

Pediatric Reports 2012; 4:e6

doi:10.4081/pr.2012.e6

sy showed perivenular drop out but no rejection. Between the $12^{\text {th }}$ till the $18^{\text {th }}$ months after liver transplantation the child received monthly hospital admissions due to persistent symptoms. Each time the child was not febrile and the investigation for viral enteropathogens, such as rotavirus, enteric adenovirus, cytomegalovirus and herpes simplex virus, was negative. Stool cultures for bacterial and parasitic enteropathogens were also negative. Management was with oral rehydration and a 7 day course of Trimethoprim/Sulfamethoxazole (TMP/SMX) per os $6 \mathrm{mg} / \mathrm{Kgr}$ BW/24h divided in two daily doses as prophylactic treatment, due to immunosuppression. At the age of $26^{\text {th }}$ months - 19th month after liver transplantation- on admission due to persistent symptoms, her blood count revealed $6.3 \times 10^{3}$ leukocytes with $50 \%$ neutrophils, $29 \%$ lymphocytes and $12 \%$ eosinophils $\left(756 / \mathrm{mm}^{3}\right.$ absolute count). On clinical examination eczema was noted. She underwent allergological investigation which showed elevated total serum levels of Immunoglobulin $\mathrm{E}(\mathrm{IgE})$ of $99 \mathrm{UL} / \mathrm{mL}$ (normal range $0-50$ ) and specific $I g E$ antibodies to alpha-lactalbumin and beta-lactoglobulin of $3.58 \mathrm{UL} / \mathrm{mL}$ and $16.34 \mathrm{UL} / \mathrm{mL}$ respectively (negative $<0.35)$. Specific $\operatorname{Ig} E$ to egg, soy, gluten, fish, house dust mites, grasses and moulds were absent. The results of the skin prick tests were parallel to those of specific IgE. The mother was then instructed to start a diet free of cow's milk protein and substitute milk with an extensively hydrolyzed milk formula. On follow-up her eczema deteriorated and the mother reported sporadic episodes of diarrhea. Laboratory findings included a leukocyte count of $7.4 \times 10^{3}$ with $24 \%$ eosinophils (normal $<6 \%$ ), normal liver function tests, and tacrolimus blood levels of $6.9 \mathrm{ng} / \mathrm{mL}$. The 
patient was closely monitored for milk protein avoidance and was started on an elementary milk substitute formula with marked and rapid improvement of symptoms. The following four days, eosinophils decreased to normal values. Careful interview showed that the child's mother hadn't introduced a strict milk protein avoidance diet and the child had ingested several milk containing foods and dairy products.

At the age of 9.5 years cytokine assessment revealed a cytokine production toward T-helper 2 cell (Th2) immune response characterized by elevated levels of interleukin $4(I L-4)$ and (interleukin 13) $I L-13$, normal (interleukin 5) $I L-5$ and slightly elevated interferon-gamma $(I F N-\gamma)$. Determination of specific IgE antibodies to milk proteins showed that they were still moderately elevated. The regulatory cytokines (interleukin 10) $I L-10$ and the transforming growth factor-beta (TGF- $\beta$ ) were also elevated (Table 1). Six months later reassessment of specific IgE antibodies to milk proteins showed that the titers were negative. She received hospital admission and she underwent a milk challenge test which was negative. She has not been avoiding milk and dairy products ever since.

\section{Case \#2}

Is an 18-year-old boy who received a liver graft at 6 months of age due to extra-hepatic biliary atresia. The deceased donor had no known history of atopy. The patient had been receiving orally an immunosuppressive regimen of cyclosporin $2-6 \mathrm{mg} / \mathrm{Kgr} /$ day and methylprednisolone at $0.1 \mathrm{mg} / \mathrm{Kg} /$ day before he was switched to tacrolimus at $0.15-0.3 \mathrm{mg} / \mathrm{Kg} / \mathrm{day}$ achieving a serum level of $3 \mathrm{ng} / \mathrm{mL}-9.2 \mathrm{ng} / \mathrm{mL}$ and methylprednisolone. The child and his family had no history of any allergic disease. After transplantation the patient followed an unrestricted diet without any signs of adverse reactions to foods. Patient's post-operative course was uneventful. On follow ups his liver enzymes were normal and liver biopsies performed every 3 years have not shown signs of rejection.

At the age of 16 years the patient complained of abdominal pain and discomfort and occasionally nausea and vomiting after ingesting milk and dairy products. On clinical examination no hives or eczema was present. His abdominal ultrasound showed a normal liver structure and the Doppler ultrasonography showed unrestricted blood flow in the hepatic artery and portal vein. Laboratory investigation showed not elevated liver enzymes and normal PT and PTT values. He revealed total serum $\operatorname{Ig} E$ of $250 \mathrm{UL} / \mathrm{mL}$ (normal range $0-100$ ) without eosinophilia, as the absolute count was $117 / \mathrm{mm}^{3}$ (normal $<500 / \mathrm{mm}^{3}$ ) and specific $\operatorname{Ig} E$

Table1. Cytokine assessment in the 3 pediatric cases.

\begin{tabular}{lccc}
$\begin{array}{l}\text { Cytokine } \\
\text { concentration }(\mathrm{pg} / \mathrm{mL})\end{array}$ & Case \#1 (age 9.5) & Case \#2 (age 16) & Case \#3 (age 12) \\
$I L-2$ & $7.8 \mathrm{normal}<46$ & 9 normal $<48$ & 14 normal $<46$ \\
$I N F-\gamma$ & $18 \uparrow$ normal $<11$ & $20 \uparrow$ normal $<16$ & $17 \uparrow$ normal $(3-16)$ \\
\hline$I L-4$ & $54 \uparrow$ normal $<13$ & $100 \uparrow$ normal $<45$ & 28 normal $(0-45)$ \\
$I L-13$ & 17 normal $<23$ & 20 normal $<60$ & 7.7 normal $<23$ \\
\hline$I L-10$ & $14 \uparrow$ normal $<4$ & $21 \uparrow$ normal $<10$ & $9.1 \uparrow$ normal $<4$ \\
$T F G-\beta$ & $20 \uparrow$ normal $<13$ & 19 normal $<20$ & $18 \uparrow$ normal $(0-10)$ \\
\hline
\end{tabular}

IL, interleukin; INF- $\gamma$, interferon-gamma; TFG- $\beta$, transforming growth factor- $\beta$.

antibodies to milk of $3.78 \mathrm{UL} / \mathrm{mL}$ (negative $<0.35)$. He was placed on a milk elimination diet with complete resolution of his symptoms. Two years later at the age of 18 the level of specific IgE antibodies to cow's milk were 0.78 UV/mL. A moderate amount of cow's milk protein was reintroduced in the patient's diet without reoccurrence of his previous symptoms.

Assessment of cytokine production showed an enhanced T-helper 1 cell (Th1) immune response, as IFN- $\gamma$ was moderately elevated without accompanying downregulation of Th2 cytokines, as $I L-4$ and $I L-13$ were elevated at the time when cow's milk allergy diagnosis was established. The regulatory cytokine TGF$\beta$ was within the normal range (Table 1).

\section{Case \#3}

The third case involves a 12-year-old girl who underwent OLT for extrahepatic biliary atresia at 8 months of age. The living donor was her mother who had no personal or family history of atopy. The patient has been on tacrolimus immunosuppression for the last eleven years achieving a serum level of 4 $\mathrm{ng} / \mathrm{mL}$. She experienced the first allergic reaction almost 2 years after transplantation when she was about 3 years old. When she ingested a piece of candy made of sesame seeds she presented with lip swelling, facial angioedema and hoarseness of voice. She was managed with intramuscular Adrenalin injection and corticosteroids. She has been avoiding sesame and no accidental exposures occurred ever since. The child presented similar symptoms when she was drinking milk or when ingesting dairy products, white fish and egg proteins. Detection of specific $\operatorname{Ig} E$ antibodies to various foods showed by the age of 3 years elevated levels of specific $\operatorname{Ig} E$ antibodies to milk, egg, white fish, pork and chicken.

At the age of 5 years the level of specific $\operatorname{Ig} E$ antibodies to cow's milk decreased significantly at the level of $0.78 \mathrm{UL} / \mathrm{mL}$ and she has been able to tolerate milk ever since. At the age of 11 years she started to tolerate well cooked egg but she was still unable to tolerate raw egg. Total serum $\operatorname{Ig} E$ was at the level of $992 \mathrm{UV} / \mathrm{mL}$ and the absolute eosinophil count was $195 / \mathrm{mm}^{3}$ (normal $<500 / \mathrm{mm}^{3}$ ). In spite of the moderately elevated specific $\operatorname{Ig} E$ antibodies to pork and chicken the patient has always been able to tolerate them and her diet in regards to pork and chicken has never been restricted.

Cytokine assessment showed increased levels of the regulatory cytokine $T G F-\beta$, an enhanced Th1 immune response toward IFN- $\gamma$ production and normal Th2 cytokines (Table 1).

Conclusively, sensitization to milk protein in our cases occurred in children who received liver grafts from donors with no known history of food allergy. The long term follow up was 9.5 years in the first case, 17.5 years in the second case and 11 years in the third case. Food allergy diagnosis was established in all the patients by assessing the specific $\operatorname{Ig} E$ antibodies to common food allergens and by evaluating the patient for resolution of the allergic symptoms. Eosinophilia was present in only one patient who had a persistent allergy to cow's milk protein which resolved after eight years. The onset of allergy became evident when the patient was 19 months old in the first case and 16 years old and 3 years old in the second and third case respectively. The duration of symptoms was 8 years in the first case and 2 years in the other two cases. All the patients had an enhanced Th1 dominant immune response before achieving tolerance. High total serum $\operatorname{Ig} E$, elevated specific $\operatorname{Ig} E$ antibodies to various food allergens and the use of tacrolimus as immunosuppressive regimen was a common feature in all our cases.

\section{Discussion}

Type I allergic reactions to common food allergens have increasingly been reported in transplant recipients, mainly in orthotopic liver transplanted children.2,5-11 The transfer of allergy from a food allergic liver donor to a previously non allergic liver transplant recipient was first reported in 1997. 6 The only reports of acquired food allergy in adults after liver trans- 
plantation have occurred via passive transfer from food allergic liver donor, whereas acquired food allergy after liver transplantation has been widely reported in children receiving liver transplants from donors with no known food allergy.

Tacrolimus mechanism of action involves the inhibition of a protein phoshatase, calcineurin, which results in repression of an early step of $\mathrm{T}$ cell activation. Although its administration usually produces a therapeutic immunosupression, a paradoxical elevation of total serum $\operatorname{Ig} E$ was observed in these patients. Another explanation could be that the transplanted liver retains sufficient allergen specific $I g E$ in its large vascular pool to sensitize the recipient's mast cells. Although IgE circulates in the peripheral blood for only a few days, it remains bound to high affinity receptors on tissue mast cells for several months. However, the transplanted liver contains not just donor $\mathrm{T}$ and B lymphocytes, but also dendritic cells and pluripotential hematopoietic stem cells capable of surviving for several months after liver transplantation. These cells could possibly migrate to the recipient's lymphoid organs or other sites and there provoke recipient sensitization. 12

Eosinophilia was present in one of the three patients receiving tacrolimus immunosupression the other two patients had normal eosinophil count while peripheral blood eosinophilia has been frequently observed in patients with post-transplant food allergy. The high prevalence of eosinophilia in tacrolimus treated patients supports the hypothesis that the cases of new onset food allergy are a result of calcineurin inhibitor imbalance between Th1 and Th2 helper cells and not a result of passive transfer of sensitized donor lymhocytes in the transplanted organ. ${ }^{13}$ Tacrolimus binds to immunophilins (proteins that bind to immunosuppressive drugs) termed FKBP-FK binding proteins. This complex then binds to and inhibits the activity of calcineurin, a serine threonine phosphatase that plays a critical role in interleukin 2 (IL-2) promoter induction during T-cell activation. 14

The immunological investigation by cytokine assessment showed that a Th1 immune response toward $I F N-\gamma$ was present in all patients. The first two patients showed a Th2 cytokine dominance characterized by elevated $I L-4$, while the third patient revealed a normal serum $I L$ - 4 level when she became tolerant to various food allergens. The regulatory cytokine TGF- $\beta$ was elevated in the first case shortly before the patient became tolerant to cow's milk proteins and also in the third case when the patient outgrew her allergy (Table 1). The mechanism of tolerance to food is not completely understood. It is suspected that Tregulatory cells are involved in tolerance acquisition. The hypothesis for a key tolero- genic role of regulatory T-cells has been reinforced by studies showing that children having outgrown food allergy with mostly gastroenterologic symptoms, have increased number of CD4+CD25+ T-regulatory cells in their gut mucosa. Regulatory T lymphocytes will secrete $I L-10$ and $T G F-\beta$ which may downregulate the $I g E$-driven reactions. Promoting the $I L-10$ rich environments in the gut seems to be an option to prevent or even treat food allergy. 15 The regulatory cytokine $T G F-\beta$ was an early marker of tolerance acquisition in the two patients.

The first patient who had a positive family history of atopy and eosinophilia suffered from persistent food allergy, while the other two patients who had normal eosinophil count in the peripheral blood and a negative family history of atopy suffered from a more transient type of food allergy. Factors such as peripheral eosinophilia and a positive family history of atopy were related to persistent PTFA in our patients.

In the second case the onset of food allergy was delayed .The diagnosis in this case was based on the patient's gastrointestinal symptoms, the exclusion of other diagnosis and by taking into account the elevated level of the specific $\operatorname{Ig} E$ antibodies to milk proteins. The diagnosis was supported by the resolution of the patient's symptoms when a milk protein elimination diet was introduced. Achievement of tolerance was determined by assessing the levels of specific IgE antibodies to milk proteins. Although a proper challenge has not been carried out, when the level of specific $\operatorname{Ig} E$ antibodies to milk proteins became negative, the patient's diet relaxed with no adverse events. The level of the specific IgE antibodies to food proteins proved to be a useful marker for monitoring food allergy in all our cases. Low levels of specific Ig $E$ antibodies to the previously implicated food proteins were related to a successful reintroduction of the foods in the patient's diets.

Transplant acquired food allergies are not uncommon in pediatric liver recipients. ${ }^{2,10,13-}$ 14,16-20 Health providers should have increased suspicion of the complication in liver transplanted children in order to make an appropriate investigation and follow up. The long term prognosis of acquired food allergy in pediatric liver recipients is currently obscure. A letter to the editor of JACI 2008 by FrischmeyerGuerrerio P, et al. ${ }^{21}$ reports that 23 out of 25 children followed given diagnosis of food allergy after organ transplantation were able to follow unrestricted diets after a median duration of 2.4 years follow up in the clinic and 6.1 year by telephone. Maarof et al. 22 in 2011 reported that $\operatorname{Ig} E$-mediated multiple food allergy after liver transplantation could be efficiently managed after switch from tacrolimus to cyclosporine immunosuppressive regimen with an elimination diet. The prognosis of
PTFA of the 3 patients followed in our clinic so far has been excellent. All our patients remained on tacrolimus immunosupression. They were all placed on elimination diets of the offending food allergens and they all achieved tolerance after a long term follow up. The onset of allergic reactions to cow's milk protein was 19 months old,16 years old and 3 years old in cases 1.2 and 3 respectively. Cow's milk allergy persisted for 8 years in the first case and for 2 years in the other two cases.

Development of food tolerance in patients with acquired food allergies after a liver transplant remains an important issue. The patients themselves and health care providers often report that restricted diets have a significant impact on their quality of life. Families of transplanted patients with acquired food allergies always address questions to physicians who provide follow up in regards to food tolerance acquisition. The prognosis of PTFA has not been well established so far. Only limited data are available in regards to the prognosis of PTFA and more studies including greater number of patients are required in order to establish the long term outcome of PTFA in pediatric liver recipients.

\section{References}

1. Prabakharan K, Lau HT, Wise B, et al. Incidence of allergic symptoms in pediatric liver transplant recipients treated with tacrolimus based immunosuppression. Pediatrics 1999;104:786-7.

2. Boyle R, Hardikar W, Tang M. The development of food allergy after liver transplantation.Liver Transpl 2005;11:326-30.

3. Agosti JM, Sprenger JD, Lum LG, et al .Transfer of allergen-specific IgE-mediated hypersensitivity with allogeneic bone marrow transplantation. N Engl J Med 1988; 319:1623-8.

4. Collins RH, Jr, Anastasi J, Terstappen LW, et al. Brief report: donor derived long term hematopoiesis in a liver transplant recipient. N Engl J Med 1993;328:762-5.

5. Lacaille F, Laurent J, Bousquet J. Lifethreatening food allergy in a child treated with FK 506. J Pediatr Gastroenterol Nutr 1997;25:228-9.

6. Legendre C, Callait-Zucman S, Samuel D, et al. Transfer of symptomatic peanut allergy to the recipient of a combined liver-andkidney transplant. N Engl J Med 1997;337: 822-4.

7. Nowak-Wegrzyn AH, Sicherer SH, Conover-Walker MK, et al. Food allegy after pediatric organ transplantation with tacrolimus immunosuppression. J Allergy Clin Immunol 2001;108:146-7.

8. Phan TG, Strasser SI, Koorey D, et al. 
Passive transfer of nut allergy after liver transplantation. Arch Intern Med 2003; 163:237-9.

9. Trotter F, Everson G, Bock A, et al. Transference of peanut allergy through liver transplantation. Liver Transpl 2001; 7:1088-9.

10. Lykavieris P, Frauger E, Habes D, et al. Angioedema in pediatric liver recipients under tacrolimus immunosuppression. Transplantation 2003;75:152-5.

11. Pacifico L, Frediani T, Simonetti A, et al. Tacrolimus and food allergy. Transplant 2003;76:1778.

12. Atkins MF. Systemic FK 506 and Post Transplant Food Allergy in Children. J Paediatr Gastroenterol Nutr 2003;37:525-6.

13. Granot E, Yakobovich E, Bardenstein R. Tacrolimus immunosuppresson - an association with asymptomatic eosinophilia and elevated total and specific IgE levels. Paediatr Transplant 2006;10:690-3.
14. Saeed SA, Integlia MJ, Pleskow RG, et al. Tacrolimus-associated eosinophilic gastroenterocolitis in pediatric liver transplant recipients: role of potential food allergies in pathogenesis. Pediatr Transplant 2006;10:647-9.

15. Eigenmann PA. Mechanisms of food allergy.P ediatr Allergy Immunol 2009;20:5-11.

16. Dehlink E, Gruber S, Eiwegger T, et al. Immunosuppressive therapy does not prevent the occurrence of immunoglobulin Emediated allergies in children and adolescents with organ transplants. Pediatrics 2006;118:e764-70.

17. Romero R, Abramowsky CR, Pillen T, et al. Peripheral eosinophilia and eosinophilic gastroenteritis after pediatric liver transplantation. Pediatr Tranplant 2003;7:484-8.

18. Arikan C, Kilic M, Tokat Y, et al. Allergic disease after pediatric liver transplantation with systemic tacrolimus and cyclosporine therapy. Transplant Proc
2003;35:3039-41.

19. Ozdemir 0, Arrey-Mensah A, Sorensen RU. Development of multiple food allergies in children taking tacrolimus after heart and liver transplantation. Pediatr Transplant 2006;10:380-3.

20. Blanchard SS, Gerrek M, Czinn S, et al. Food protein sensitivity with partial villous atrophy after pediatric liver transplantation with tacrolimus immunosuppression. Pediatr Transplant 2006;10:529-32.

21. Frischmeyer-Guerrerio P, Wisniewski J, Wood R, et al. Manifestations and longterm outcome of food allergy in children after solid organ transplantation. J Allergy Clin Immunol 2008;122:1031-33.

22. Maarof G, Kizysiek R, Decline JL, et al. Management of post-liver transplant-associated IgE-mediated food allergy in children. J Allergy Clin Immunol 2011;127: 1296-8. 